\title{
Making and Using Slides in the ESL Classroom
}

Joyce Cunningham

Posters are expensive, guest speakers rare and photos limited to those few students within eye range. The use of slides can present a welcome solution to teachers and students alike. They provide an interesting variation from classroom routine and cognitiveoriented exercises. The colourful visual element of slides encourages the imagination and distances students from too great a dependency on the written word.

Slides can supplement intensive and evening ESL programmes and can be used to teach a variety of themes, everyday subjects and specific structures. This article is aimed especially at the high Beginner and low Intermediate level learners and should be of interest to instructors ranging from the secondary to adult education departments. Techniques encompassing the four skills are outlined. Finally, the possibility of using teacher or student-made slides generated by special projects is considered.

\section{Introduction}

Many instructors have had some unpleasant moments with slides. We all remember those "wonderful" slide shows of our neighbour's trip or those long, long, long teacher-centered sessions when we ourselves were students. Needless to say, a long time went by before I began to consider even using slides in my courses.

\section{Visual options and drawbacks:}

When teaching ESL to lower levels, colourful visuals are most important for they present learners with oral possibilities beyond the mainly black and white textbooks. However, there are certain difficulties in producing interesting images that respect photocopy laws. Drawing is not given to all of us. Computer graphics do decorate a page nicely but are time-consuming, especially to those instructors who are not mechanically minded. Letraset certainly appears professional but also represents hours of extra labour-once more in black and white-and, alas and shudder, it costs money. Photos are another solution but the most carefully orchestrated atmosphere in a lesson can be quickly destroyed by the straining and pushing around the teacher to catch a glimpse of one suddenly microscopic image. Transparencies cannot render a special person or moment as vividly as one might wish. Finally, the "stories" in picture form found in beginner textbooks are, more often than not, 
the "What do they do every day?" kind of exercise. Not always very pertinent to students' lives, they may cause burnout or boredom.

It is hoped that this article will demonstrate how the use of slides will provide the instructor with useful visuals. Slides can help to facilitate oral expression by catching and encouraging the imagination of learners and distancing them from a dependency on the written word. One final reason for employing slides can be found in a passage by Bloom (1976):

If students perceive the learning tasks as new and different or as unrelated to previous learning tasks, they are likely to begin with relatively neutral or even positive affective entry characteristics in spite of their previous experiences. (p. 106)

Let us now turn our attention to some concrete suggestions on how to turn that long Friday afternoon or that blue Monday morning into a time of heightened interacting and keep learners asking for more.

\section{Topics and Techniques to exploit in the classroom:}

\section{A. Breaking the Ice:}

Some of the initial opportunities to use slides occur at the beginning of an ESL course. The activity below is especially good in a multi-cultural class where it is important for classmates to get to know each other by sharing personal information. Greater familiarity allows them to relax in one another's presence, promotes a friendlier atmosphere and creates better class dynamics. Many of us ask our learners to bring photos of their families to class. Does it not follow then, that the instructor use his/her own life and surroundings to create a setting in which students and the teacher alike will learn about each other and be enriched in the process? To this end, I compiled slides of family members who are most important to me for use when learners have studied question forms for identification (age, marital status, occupations, addresses, hobbies, etc.). The technique described below can be exploited in two different ways:

1. a. Show slides of your family to the whole class. Promise that you will NOT ramble. Explain that the question forms just studied are to be used to obtain information from you. Intermediate students can be encouraged to take brief notes. If a particular slide does not 
raise much interest, move on to the next. It is best to limit slides to a maximum of five to nine.

b. When finished or when participation begins to lag, ask your Beginners to form small groups or pairs and repeat whatever they remember. This usually has best results if students start with the slide they recall most easily.

c. This can be written up in class or given for homework.

2. Should you wish to avoid the whole class procedure, vary this activity in the following manner:

a. Divide learners up into two large groups. " $\mathrm{A}$ " works independently on a separate task or exercise. This group may be composed of weaker students who will review and practise the question forms while waiting their turn.

b. "B" views the slides with you, striving to gather as much information as possible. Set a time limit for each group. Again, depending on the level, students may or may not be required to take notes.

c. Next, "A" and "B" are alternated: "B", which has been interacting with you, returns to the classroom and " $\mathrm{A}$ " takes its place.

d. When both groups are done, learners change from the original two groups into pairs (one " $\mathrm{A}^{n}$ and " $\mathrm{B}$ " are now together). Information is compared.

e. An information gap can create an interesting twist to this activity. In a higher beginner or low intermediate class, challenge students to listen even more closely to you and each other. AFTER both large groups have finished step 2.b., tell them that slightly different answers have been given to several of the common questions asked. One " $A$ " and one "B" then compare so as to discover what these differences might be.

\section{B. Nationalities:}

A second opportunity to use slides occurs early on in my course when teaching nationalities. The technique is as follows:

a. Select slides of ethnic groups from your area or from your travels.

b. Quickly run through the slides with the class. Encourage learners to guess what ethnic communities or countries are being viewed. This activity is excellent for a mixed class composed of many nationalities and French Canadians (who may have come into only limited contact with foreigners).

c. If interest has been caught during the first viewing, show the slides again, using a worksheet with questions on the activity in each 
slide and its significance. (Stronger classes can be asked to view the slides a second time and jot down individually what they believe to be happening.) This additional viewing will encourage further guessing and toleration of ambiguity. Students then compare impressions and work to complete the worksheet.

d. Finally, learners can interview classmates from some of the countries seen in the slides. Make a general worksheet with queries on the country such as-the capital?, main food?, language?, religion?, and President?

This technique for practising nationalities should raise curiosity through its use of visual contact. A precise context is created to give meaning and reference to a second language learner's faltering words. Perceptions of other nations may be altered. The interaction and sharing of information will help to throw up scaffolding for bridges to be constructed among class members.

\section{Travelling abroad:}

Two suggestions for exploiting travel slides will be outlined below.

1. a. Before employing slides of your trip, it is a good idea to start a session with a ten to fifteen minute brainstorming session involving the whole class. Ask your Beginners to recall whatever details they can about the country to be viewed, whether it be from newspapers, magazines, T.V. or details studied in school. A stronger class may be encouraged to interview classmates-natives of the said country.

b. A small quiz of multiple choice or True/False questions will provide more vocabulary and raise curiosity even more as to the capital, the biggest city, the longest river, the national beverage or sport, etc.

c. Next, students are invited to ask questions as to your role in the country. The timing for this step is short, approximately ten minutes or less.

d. Here, attention is turned to the slides. Normally, the previous exercises will have motivated learners sufficiently so that they will continue to ask further questions throughout the viewing. The instructor should also shoulder some of the responsibility by raising those questions certain to necessitate brainsearching and comparisons. For example, one scene I treasure of an enormous Buddha in a cave in China causes much guessing as to why Buddhas are usually represented with exceedingly long earlobes. ${ }^{1}$

Natives from the country being viewed are valuable assets indeed. They can preside over the show as "experts" or "judges," permitting 
the many conjectures but, ultimately, providing the correct answer. For once, learners possess more information than the teacher! Their superior knowledge of their country greatly enriches the presentation. Even the most timid Oriental usually warms and rises to the challenge of supplying vital information. In addition, they will probably be highly amused at your strange "touristy" selection of pictures of their country.

e. When the slide show ends, students repeat orally what was understood or write it up, either in class or for homework. Stronger classes can research one aspect of the presentation which caught their interest-either by interviewing a classmate native to the country or by active reading at the library on a particular angle touched upon in the slides. Natives also stand to benefit as they can be encouraged to investigate some part of their country they previously had little time to explore.

2. A second highly successful variation involves the selection of five to seven travel slides, selected for their vacation value. Students are NOT informed of their origin for, in this way, you will avoid stereotyping or well-meaning remarks that can offend when least expected. The final objective is to make up a story of a holiday based on the slides.

a. Before watching, learners write down their ideas about ingredients necessary for an ideal or memorable vacation individually so as to avoid forgetting, or being overwhelmed by more vocal or expressive participants.

b. Pairs are then formed and requirements for a vacation and fantasies are discussed.

c. Slides are viewed one by one, pausing for a minute or two, to allow learners time to write down individually their ideas or associations.

It is important that students NUMBER each slide in order to eliminate confusion in the discussion, later on. A Beginner class can be structured even more. To make this right-brained exercise easier, ask learners to jot down two to three objects they see, the place (market, street, etc.), and what is happening (two to three actions in the present progressive). The instructor should circulate and encourage students with comments such as: "Oh, that's a good idea!" or "How funny, original, imaginative," etc. From long experience, these observations work wonders at egging learners on to greater creative efforts. 
d. When the slides are completed, groups of three are formed to compare perceptions. This works best if students begin with the slide that produced the most ideas or associations.

e. If times permits, and there is sufficient interest, have the class imagine a common group vacation or story about the slides. Two learners work together with one acting as secretary to record ideas. Before they start, you may want to show the slides again very quickly to refresh memories.

f. Change to groups of four and have stories compared. Although relatively short, the step is most enjoyable.

g. Finally, the whole class works together and proceeds slide by slide, once more. Any willing group can put forward its ideas on the first slide. Active listening is thereby encouraged for other groups will be stimulated to offer differing information. There are especially good results if students are able to volunteer or remain silent for any given slide. In general, learners are really curious and amused at each others' ideas.

h. The holiday story or ideas about each slide can be written up in class or assigned as homework.

In summary, it has been found that this activity permits imaginations to run unbridled, thus distancing students from the alltoo-often required retention of factual information. A good deal of vocabulary is generated in the group communication and, most important of all, a lot of authentic sharing and negotiation takes place.

\section{Well, what DO they do every day?}

To skirt those rather routine picture stories alluded to above, humorous slides of my best friend, my sister, were compiled. Initial surprise at not seeing the most beautiful sister in all the world (as she is labelled) releases immediate laughter, and, as we all know, laughter lubricates learning as well as breaking down barriers of fear-fear of not performing or fear of guessing and not answering correctly. The technique is as follows:

a. Pair up learners and instruct them to watch only. The question they are to answer is: "What does she do every day?" Explain first that the slides will be looked at QUICKLY so that no one will be frustrated at the speed of delivery.

b. View the slides.

c. Students work in pairs to compile a list of the everyday activities as they remember from the slides. One learner acts as secretary so that both do not immediately bury their noses in individual effort. 
d. Watch the slides again at the same quick pace. After the viewing, the pairs strive to lengthen their lists.

e. When the general noise level drops and ideas run low, new groups of four are formed. Lists are compared and meaning and structure negotiated. This step is quite exciting as there are many more possibilities that pop up and may be accepted. Vocabulary expands considerably.

f. The instructor may or may not wish to make the activity teachercentered at this point.

g. A freer discussion component can follow about what students do every day in their countries. Given the limited attention span (and toleration) of Beginners, it is advisable to change the groups of four to smaller ones. This step is one of intercultural discovery, most enjoyable to learners.

h. Students write up in class or at home their own or another classmate's day.

i. A listening component can be created by having the family member talk about what he or she does every day to expand on the slides. The teacher may either have learners simply listen and tell back what they understood in pairs or a worksheet can be prepared on the cassette. As my sister was rather long-winded, part of her information was written up in the form of a reading comprehension. j. My husband has also been "volunteered," for slides of him serve not only as a review at the end of the module on the present tense but also as a confidence builder when students realize how much more has been understood since the initial introduction to my sister. Finally, the masculine context does necessitate sightly different vocabulary.

In summary, this technique has encompassed the four skills in such a manner as to vary lessons in an original and personalized fashion. The response from the class is most favourable.

You may wish to review the present tense (and company) at the end of the course. Why not exploit the activity mentioned above from a more creative, abstract angle? Experiment with objects representative of the action suggested. Thus, a slide of an alarm clock can bring to mind a wide range of possibilities, as can slides of the bathroom (no person within), a coffee pot, a coat in a closet, etc. Using their imaginations, learners interpret what is suggested by each slide.

This exercise serves as a self-testing device, especially if repeated near the end of a unit or course. Students, hopefully, will become more aware of their own progress. Thus, this last abstract viewing 
will act as a confidence builder in which learners perform well on less familiar ground.

\section{E. Guessing:}

In order to change pace between normal class exercises which have demanded a lot of concentration or to save a lesson plan which may have "bombed" dismally, the following two activities can be inserted, using interesting slides that do not necessarily fit into any given category. These are employed for guessing and prediction.

1.a. Slides of people are put up onto a screen. Students study the subject individually for a minute or so, reflecting upon the age, mood, thoughts or actions of the person. Ideas are jotted down in note form.

b. Two learners then exchange opinions.

c. Pairs are changed several times more. Students appear more articulate each time groups are changed and usually seem more relaxed as the struggle with language eases somewhat with each additional practice.

d. Finally, you might want learners to discuss and even role-play what they believe is happening or about to happen in the slide.

2. Slides may be blurred to elicit guessing. The slide evolves slowly from very out of focus to lesser degrees of blurring. You can take advantage of this activity to teach or review the gambits of agreement or disagreement. If a student has hit the nail on the head early on, before the others, the instructor can ask the other members of the class if anyone agrees with the opinion expressed in order to generate more discussion. ${ }^{2}$

\section{F. Canada: cultural content:}

There are numerous aspects of Canada that can be explored through slides to bring about greater awareness of the Canadian society and its expectations. Suggestions for exploiting some of these areas will be mentioned below.

1. Slides of Canada from coast to coast:

Familiarization of Canadian geography is much more enjoyable when students are able to react immediately to colourful slides of our provinces. The Audio-visual Department of most universities or community colleges can advise you how to take slides from photos, post cards, calendars, etc. The procedure mentioned in Section $\mathrm{C}$ on travel slides can be adapted and employed here. 


\section{Special social events:}

Precious moments of weddings, baby showers, school reunions, graduations or others such as corn roasts, marathons, hot air balloons, Highland Games, fall fairs, sugaring offs and ethnic festivals are excellent opportunities to expose learners to the many facets of Canada in its different seasons and raise awareness and curiousity about community events. Announcements in newspapers or flyers, will provide authentic materials which inform students of community activities and double as reading comprehension.

\section{Holidays:}

Canadian holidays, too, have met with excitement and many questions. Special days such as Halloween, Thanksgiving, Christmas, Saint Patrick's Day, and Valentine's Day serve to show Canadians celebrating happy occasions in intimate settings.

You may wish to try using abstract slides to elicit information from students. To this end, a Christmas stocking hung on a mantelpiece evokes different memories from French-Canadians and other nationalities in the class. In the same way, a chimney, rum and eggs, a turkey or carollers (in the form of Christmas dolls if real subjects are scarce) can be photographed, and on and on.

The instructor should first ask Beginners to interpret what they believe to be happening in each slide. This will, most assuredly, motivate groups to exchange viewpoints and discuss variations in their own traditions. Those learners who do not observe a particular holiday can interview celebrants so as to gain information about the customs involved in each slide. A further questionnaire could be conducted in the school cafeteria, possibly in the coffee break, or at lunch time, for interaction with others and further input.

4. Seasons and weather:

Students from abroad and, certainly, those from hot countries are most inquisitive about the weather in our four distinct seasons. Pioneer Villages are an excellent source for shooting a myriad of interesting slides, for they usually feature special seasonal festivities with typical decorations and activities of settlers as well as offering demonstrations and recipes which can be exploited in the class! In addition, what better way to learn firsthand about the history of Canada than through slides?

\section{Food:}

Slides of restaurants and buffets, party spreads and special food consumed at holiday times are often easier to show than to bring into the classroom or try to explain orally. A worksheet can be created to focus on the season or festivity in which an item of food might have been eaten, what some of the ingredients might be, 
formal or informal table settings, etc. Parallels or differences can be made with the learner's own culture.

\section{Mind your manners:}

Your manners may be showing! Most teachers will probably have one family member who missed his/her vocation to star in Hollywood. Capitalize on this person to ask for help in making slides on such subjects or pet peeves as hair in curlers in public, smoking in the metro., feet up on coffee tables or desks (this still shocks Latin cultures quite a bit), applying lipstick in a restaurant, and one all instructors find hard to broach, that of ye ole underarm perspiration.

Groups can brainstorm what they think is socially acceptable or unacceptable in their countries and then, what they have experienced in Canada. French-Canadians or those with longer experience in Canada can be interviewed for more information. A questionnaire could be conducted in the school cafeteria among mainstream students to gain further insights. Thus, a real-life context containing codes of expression, gestures and clothing is provided through the medium of slides, to encourage cultural comparison, discussion and role plays as to what constitutes socially acceptable behaviour.

7. Student projects:

Learners interested in photography may be given the alternative of using their own cameras or that of borrowing one (perhaps, the instructor's) in order to produce visual presentations of a particular aspect of Canada or their own culture.

8. School trips and outings:

We all love to see ourselves starring in film whether it be in photos, slides or videos. Inform your students that, on the Friday following a school activity, a special presentation of highlights from the excursion will be offered. View this with the whole class, allowing individuals to discuss what was happening in a particular slide. Another alternative is to have small groups explain what was occurring to each other or to those who were absent. Encourage learners who have not been talking much to hazard a guess as to what someone was possibly doing or saying in a shot. The procedure suggested in C.2.c. to e. can be used here.

\section{In Conclusion:}

Slide shows do take time to build but they are most rewarding for students and teachers alike. They are an extremely effective visual variation in any ESL classroom when pedagogical objectives as well 
as learners' needs and attention spans are kept in mind. If founded on communicative techniques, slides can enrich lesson plans and will provide additional practice with special structures. They will generate a good deal of basic vocabulary while featuring real and loved people known to the instructor. Most of all, slides explore authentic daily situations about which students can talk, interact, speculate and draw their own conclusions. Greater awareness of Canadian contexts and of classmates' multicultural backgrounds is encouraged. Finally, the sharing among students will often result in better class dynamics, benefitting all concerned.

\section{NOTES}

1. Both The mind's eye and The dynamics of human communication suggest alternatives for exploiting pictures along the lines mentioned.

2. Ibid.

\section{REFERENCES}

Bloom, B. (1976). Human characteristics of school learning. Toronto: McGraw-Hill.

Bullough, R. (1988). Creating instructional media. (3rd ed.). Columbus, Ohio: Merrill Publishing Co.

Coles, M. (1991, February 23). Slides can be spectacular but if you're having a show, pick only the best shots for display. The Gazette. p. L3.

De Bloomis, M. (1983). Single frame video for language instruction. Calico Journal, I (1), 7-9.

Griffith, J., Miner, L. \& Strandberg, T. (1975). Classroom projects using photography: Part 2, for the secondary school. New York: Eastman Kodak Co. 
Kemp, J., \& Smellie, D. (1989). Planning, producing and using audioinstructional media. (6th ed.). N.Y.: Harper \& Row.

Maley, A., Duff, S., \& Grellet, F. (1980). The mind's eye. Cambridge: Cambridge University Press.

Myers, G., \& Myers, M. (1980). The dynamics of human communication: a laboratory approach. New York: McGraw-Hill.

Painchaud, G. (1987, January). Lecture given for the course "Recherches en Education des Adultes" at the Dept. of Andragogy, University of Montreal, Montreal.

Rubin, J., \& Wenden, A. (Eds.). (1987). Learner strategies in language learning. Englewood Cliffs, N.J.: Prentice Hall.

Wileman, R. (1980). Exercises in visual thinking. New York: Hastings House Publishers.

Williams, C. (1963). Learning from pictures. Washington: Dept. of Audiovisual Instruction.

Wright, A. (1976). Visual material for the language learner. London: Longman.

Zettersen, A. (1986). New technology in language teaching. New York: Pergamon Press.

\section{THE AUTHOR}

Joyce Cunningham specializes in ESL Beginners at McGill and Concordia Universities. She taught EFL one year in Beijing for CIDA. She holds a Masters Degree in French and Spanish literature and recently completed an M.Ed. in Adult Education from the University of Montreal. For the past six years, she has worked as a consultant for a publishing company, an affiliate of Longman International, in Montreal. 